Yu T., Sousa H.S., Branco J. (2020). Combination of non-destructive tests for assessing decay in existing timber elements. Nondestructive Testing and Evaluation 35(1). pp 29-47. (doi.org/10.1080/10589759.2019.1635593)

\title{
Combination of non-destructive tests for assessing decay in existing timber elements
}

\author{
Yu Taoyi ${ }^{\mathrm{a}, \mathrm{b}}$, Hélder S. Sousa ${ }^{\mathrm{a}^{*}}$, Jorge M. Branco ${ }^{\mathrm{a}}$ \\ ${ }^{a}$ Department of Civil Engineering, ISISE, University of Minho, Portugal \\ ${ }^{b}$ International Research Center for Architectural Heritage Conservation, Shanghai \\ Jiao Tong University, Shanghai, China \\ * corresponding author: ISISE, University of Minho, Department of Civil Engineering, \\ Azurém, 4800-058 Guimarães, Portugal \\ e-mail: sousa.hms@gmail.com
}

Tel: +351253510200 ; Fax: +351253510217

e-mail addresses: $\quad$ Yu Taoyi - eta.yu@icloud.com

Hélder S. Sousa - sousa.hms@gmail.com

Jorge M. Branco - jbranco@civil.uminho.pt 


\title{
Combination of non-destructive tests for assessing decay in existing timber elements
}

\begin{abstract}
Existing timber structures often present elements with different levels of decay and the choice to maintain them comes from the structural assessment, made by a civil engineer on the basis of the results coming from the on-site survey. The choice may also rely on visual inspection combined non-destructive tests. In that case, the choice to maintain an element will greatly depend on the accuracy and reliability of the results obtained through these tests. This work aims to assess the properties of timber elements through non-destructive tests, using resistance drilling, pin penetration, ultrasound, and acoustic emission tests. The tests were carried out on three timber elements from two old timber roof trusses. The results are analysed regarding the specimen size and the use of multiple non-destructive test parameters. Decay was initially identified by means of visual inspection and different levels of decay were identified taking into account their influence on the non-destructive test results and on the predictability of models based on single and multiple regression analysis. Moreover, the obtained classification was found to increase the reliability on the prediction of density.
\end{abstract}

Keywords: Timber structures, non-destructive test, decay, correlation, experimental evaluation

\section{Introduction}

Timber constructions have an important significance in the cultural, architectural and historical heritage in different civilizations, with numerous examples of structures still standing. As the first step for their safety assessment and conservation, it is important to find out the physical and mechanical properties of the timber elements. For old timber elements, without any reference value given by producers as in the case of new wood base material, engineers have to carry out an on-site evaluation of their properties according to its origin, growth conditions, carpentry skills, service conditions along time, natural defects, among others. Moreover, as a biological material, timber can present various types of damages caused by insect attack and fungi attack (decay), or even by temperature and moisture change (resulting in cracks). The distinct types and existence 
of decay at different levels also intensify the need for in situ assessment for timber structures (Kasal and Tannert, 2010).

An accurate way to obtain the mechanical properties would be to conduct destructive tests such as density measurement, compressive, tensile, or bending on samples extracted from those elements. However, this would inevitably damage the original elements and structure and also it must be noted that small clear wood specimens may not be entirely reliable for the assessment of the performance of full scale timber elements, where defects and state of conservation take an important role. In that case, non-destructive tests (NDTs), with little compromise on the integrity of the tested elements, have long been adopted for assessing timber properties, mostly qualitative but also quantitatively.

Researches on quantitatively predicting timber physical and mechanical properties by NDT parameters can be found in Kloiber, et al. (2015) and Cavalli and Togni (2013) for pin penetration test, Nowak, et al. (2016) for resistance drilling tests, Ruy, et al. (2018), Morales-Conde and Machado (2017), and Salmi, et al. (2013) for ultrasound test, and Kawamoto, et al. (2002) and Lamy et al. (2015) for acoustic emission test. However, concluding that the various types of decay, which are frequently present in existing timber structures, would significantly influence the NDT results and their accuracy on the prediction of timber properties, researches started to focus on the influence of the conservation state of old timber elements such as in Gomes, et al. (2016), Cavalli, et al. (2016), Zhong, et al. (2017), and Zhang, et al. (2015). Moreover, decay assessment using NDTs was researched in Branco et al. (2017) and Sousa et al. (2017) where, through the use of damage maps, it was possible to pinpoint regions of the structure and even of segments of the elements which had different levels of decay and their probable sources. To analyse the variation of timber properties along one element, due to different levels of conservation, scale and natural variability of wood, some of the more recent studies tried different prediction models, such as Sousa, et al. (2015) and Sousa et al. (2018) with hierarchical models and probabilistic models using Bayesian methods, García-Iruela, et al. (2016) and Miguel, et al. (2018) with artificial neural networks. Furthermore, some research already showed the promising results using combination of different NDTs, such as Cavalli and Togni (2013) found that using pin penetration depth and stress wave velocity, the prediction of bending modulus is high, and Vega, et al. (2012) also found the highest predictability of bending modulus by the combination of vibration wave velocity, density and sample length. However, more other 
possible NDT combinations (such as resistance drilling and ultrasound tests) were not addressed.

In this paper, a combination of NDTs (drilling resistance, pin penetration, ultrasound, and acoustic emission tests) was considered for the analysis of three timber elements which were dismantled from two existing timber roof trusses of a building from the 18 th century. The results were combined and then correlated with the physical and mechanical properties derived from destructive tests. Linear and multiple regression models were considered to evaluate different levels of decay and the results are analysed dependant on the presence of defects (knots, superficial cracks and ring shakes) and decay (from fungi and/or insect attack), and on how they affect the timber properties, the NDTs results, and the correlation between them. The objective of this work, is to provide practitioners and researchers with an indication of the increase of value on the choice of using a single non-destructive test or a specific combination of tests, as to allow for a better identification of the extent and severity of damage and decay on existing timber elements. This procedure may be included in the preliminary assessment of existing timber structures, just after or in combination with visual inspection. Guidelines for assessment of existing timber structures where this framework may be incorporated are exemplified in Cruz et al. (2015), Sousa et al. (2016) and Riggio et al. (2018). For instance, the on-site assessment of timber structures can be categorized into four hierarchical levels, namely as system, unit, element, and connections (Riggio et.al, 2018). However, for existing structures the mechanical characterization at element level, requires no or minimum compromise on the integrity of the original element. Hence, different complementary approaches can be adopted, such as proof loading, visual grading, and non-destructive tests.

\section{Material and methods}

\subsection{Material}

The tested timber elements were taken from two timber roof trusses of the Chimico Laboratory, a Portuguese neoclassic building of the 18th century (Lourenço, et al. 2013). After inspection onsite, the Maritime Pine (Pinus pinaster) timber trusses were evaluated to be in poor conservation state and thus dismantled and replaced by new ones. From two of the trusses, three elements were chosen for this research, due to their large variability 
of visible decay along their length, as shown in Figure 1a). As shown in Figure 1b), the three elements had different structural uses within the trusses. One element was used as the collar beam of Truss A (Element 2), and two others as rafters. One of the rafters was on the south façade of the building (Element 1 from Truss A), while the other was on the north façade (Element 3 from Truss B). The dimensions of each element are shown in Table 1. The number of specimens was limited to the availability of material and the applicability of the results must be considered attending to this limitation. However, it is noted that the sample for analysis corresponds to the segments and cross-sections of the elements, thus increasing its representativeness in terms of sample size. Nevertheless, even if the presented framework is consistent, it is assumed that the dependence of results is greater within the segments of the same element and thus the results presented in this work are reliably applicable to this sample but may less reliable for elements with different levels of decay, age and species.

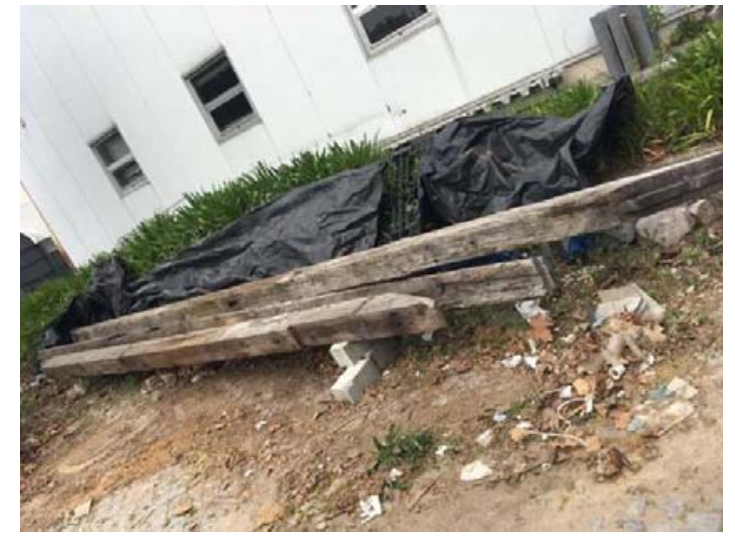

a)
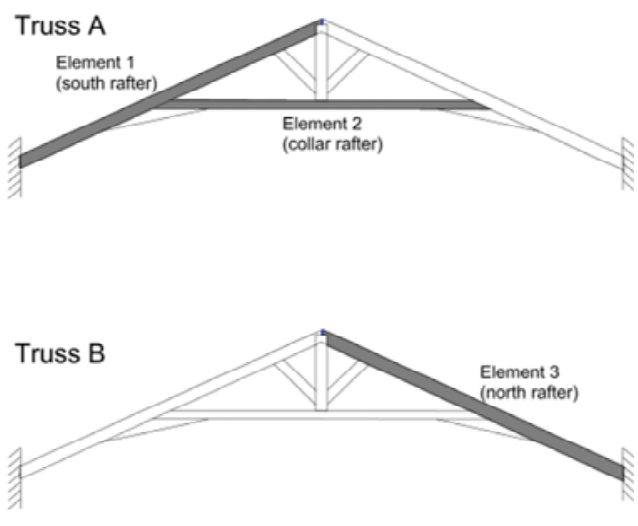

b)

Figure 1 - Tested elements: a) onsite photo b) representation of the original trusses and location of the elements

Table 1 - Dimension of the three elements

\begin{tabular}{|c|c|c|c|c|c|c|c|c|c|}
\hline \multirow{2}{*}{$\begin{array}{l}\text { Dimension } \\
\quad(\mathrm{cm})\end{array}$} & \multicolumn{3}{|c|}{ Element 1} & \multicolumn{3}{|c|}{ Element 2} & \multicolumn{3}{|c|}{ Element 3} \\
\hline & Depth & Height & Length & Depth & Height & Length & Depth & Height & Length \\
\hline Maximum & 20.5 & 23.5 & \multirow{4}{*}{632.0} & 20.5 & 23.5 & \multirow{4}{*}{817.3} & 21.0 & 26.0 & \multirow{4}{*}{772.5} \\
\hline Minimum & 18.0 & 9.0 & & 19.0 & 9.5 & & 17.0 & 19.5 & \\
\hline Mean & 19.7 & 21.9 & & 19.7 & 21.6 & & 20.0 & 24.0 & \\
\hline $\mathrm{CoV}$ & 0.03 & 0.14 & & 0.02 & 0.13 & & 0.05 & 0.06 & \\
\hline
\end{tabular}




\subsection{Methods}

\subsubsection{Framework}

Figure 2 shows the framework proposed for this study. In this study two different type of destructive tests (DTs) were made, namely density measurement and bending test. The bending tests were made to the full size elements in order to obtain the modulus of elasticity (MoE), whereas the density measurements were made considering the extraction of specimens from the elements. It must be noted that to obtain the MoE in bending, the test itself is not destructive as it is made only on the elastic range. However, the need to remove an element from the structure (or a small specimen) is a destructive procedure. Density and bending MoE were considered in this analysis as they are two key properties that define the mechanical behaviour of timber elements and are currently used in grading schemes as input information (JCSS, 2006). Those properties were then correlated with the parameters resulting from the NDTs, which were visual inspection, drilling resistance, pin penetration, ultrasound, and acoustic emission tests. Moreover, special attention was paid to the presence of decay, either if it was only superficial or with significant indepth penetration. The existence of exterior decay was detected through visual inspection, whereas the distinction between surface and indepth decay was initially carried out by consideration of drilling resistance tests. This information was then adopted as the criteria to separate the elements into different subsamples. To each subsample, corresponding to different levels and type of decay, the NDT and DT results are analysed and correlated. During the experimental campaign, two different phases were considered taking into account the scale of the specimens. Initially the timber specimens were tested at an element scale, where each element was visually inspected as a whole and also by giving a grading for each $25 \mathrm{~cm}$ segment. Then, on a second phase, the three elements were sawn on each $25 \mathrm{~cm}$ interval and analysed in a segment scale in order to analyse the variation of properties along the length of the element and to analyse the decay evolution within the cross-sections of the elements. The tests carried out at each phase are shown in Table 2. The objective of this framework is to provide an insight on the value of information that can be obtained by the combination of non-destructive tests for the detection and quantification of decay in existing timber structures. 


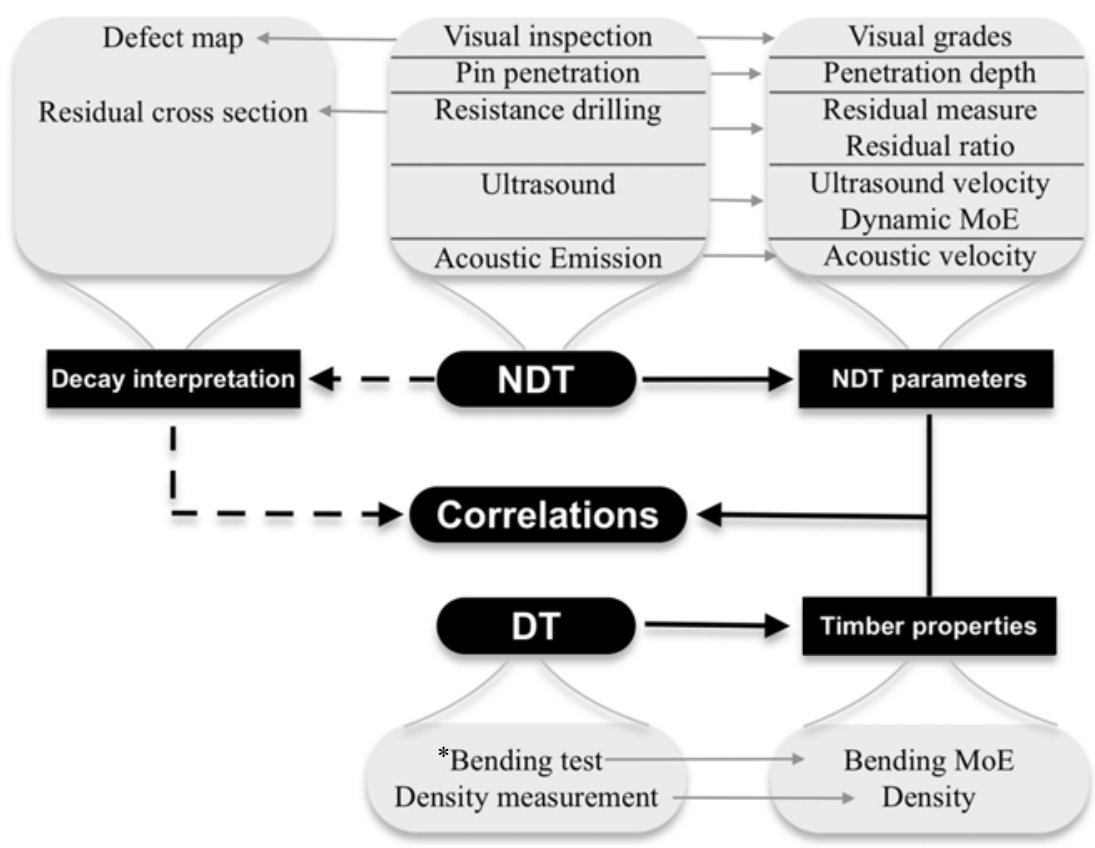

* Bending test is a DT when the member is submitted to failure to obtain bending strength. Obtaining only the bending MoE is a NDT. However, in this framework, as the test requires to remove the element from the structure itself to assess the individual member properties, the bending test was grouped within the DT.

Figure 2 - Test method scheme.

Table 2 - Test phases and considered tests

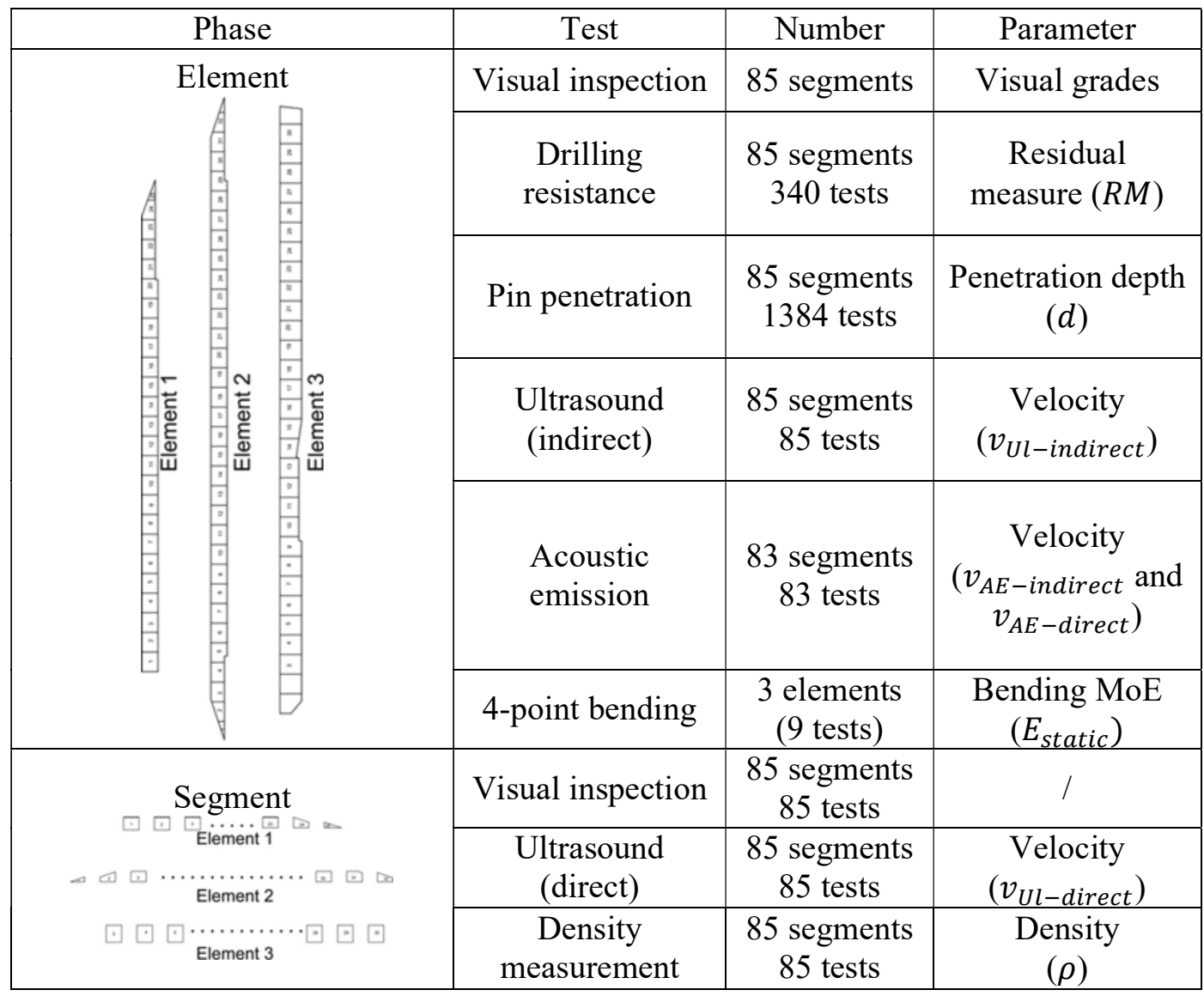


The arrangement of NDTs on the single segment and the three bending tests on Element 1, as an example, are shown in Figure 3.

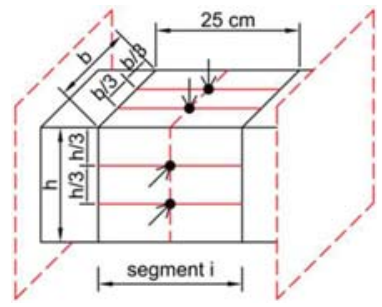

a)

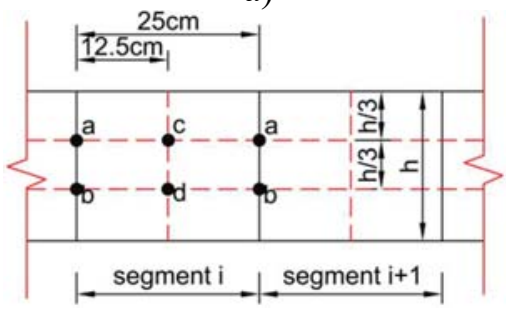

d)

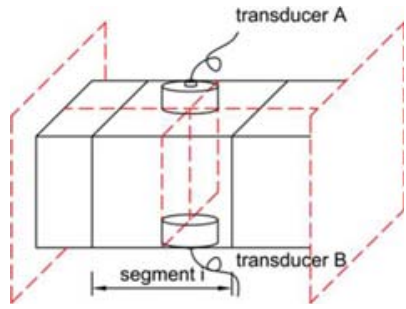

b)

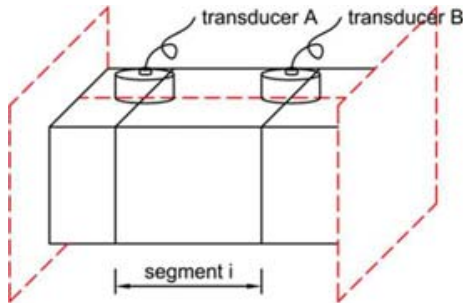

c)

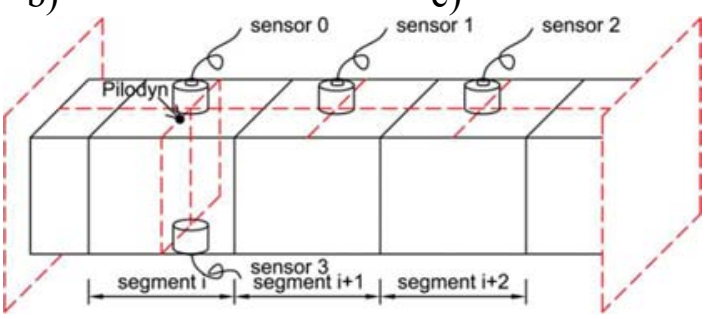

e)

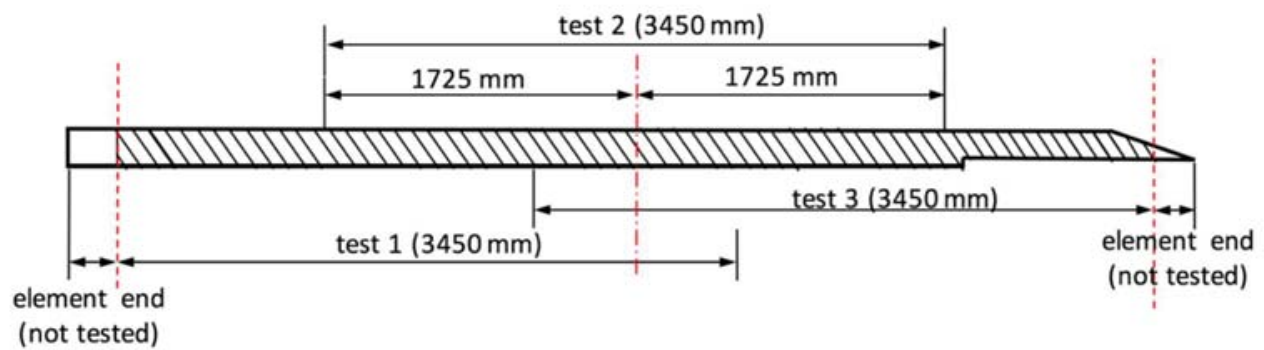

f)

Figure 3 - Test arrangement: a) resistance drilling test; b) direct ultrasound test; c) indirect ultrasound test; d) pin penetration test; e) AE; f) bending test of Element 1

\subsubsection{Non-destructive tests}

1) Visual inspection. The main purpose of conducting a visual inspection in timber a structure is to detect and typify the natural defects, consequently attributing a visual grade related to a visual strength class, to analyse the level of deterioration/damage both in terms of extension as well as intensity. In this work, defects (wanes, knots and fissures) and deterioration (by either insect or fungi attack, or its combination) were recorded for each $25 \mathrm{~cm}$ segment, as to assess the variability of these parameters along the length of the elements. A total number of 85 segments were visually inspected. 
Visual grading for each segment was determined according to the Italian standard UNI:11119 (2004), where three visual grades were considered, specified as I, II, and III. Moreover, non-classified (NC) elements were considered when the element did not comply with imposed limits for the lowest grade (grade III). In the present work, the methodology of UNI:11119 (2004) was specifically applied to each segment as to increase the sample size for statistical analysis, although the standard itself is made to assess a whole member based on the concept of critical section or segment. According to the determined visual grade and to the wood species, this standard provides indicative values for timber mechanical properties. Meanwhile, accompanied with drilling resistance tests, defect maps were generated, illustrating the level of defects and deterioration along the length of each element.

2) Resistance drilling test. Resistance drilling tests measure the energy required for penetrating a standard micro-drill into wood at a constant rotating and advancing speed. In this work, these tests were conducted with the equipment Resistograph ${ }^{\circledR} 3450$-S. The test arrangement is shown in Figure 3 a). In total, 85 segments were tested, each with 4 measurements performed at the middle section, thus totalizing 340 measurements

As a result, the residual cross-sections were determined, as the combination of drilling measurements in two directions of the same cross section allowed for a twodimensional representation of the internal part of the section, as shown in Figure 4. A residual ratio value was calculated and used to complement the information given in the damage map made by visual inspection as to evaluate the level of indepth decay presence. The residual ratio $(r)$ value was calculated by the ratio between the residual cross-section obtain by the drilling resistance tests and the apparent cross-section. The result of a drilling resistance test can also be taken by the resistance measure $(R M)$ given by the integral of the area beneath the resistance profile, thus a measurement of the energy required for drilling, with respect to the length of drilling path, $H$ (Nowak, et al. 2016) (eq. 1).

$$
R M=\frac{\int_{0}^{H} \text { Area }}{H}
$$



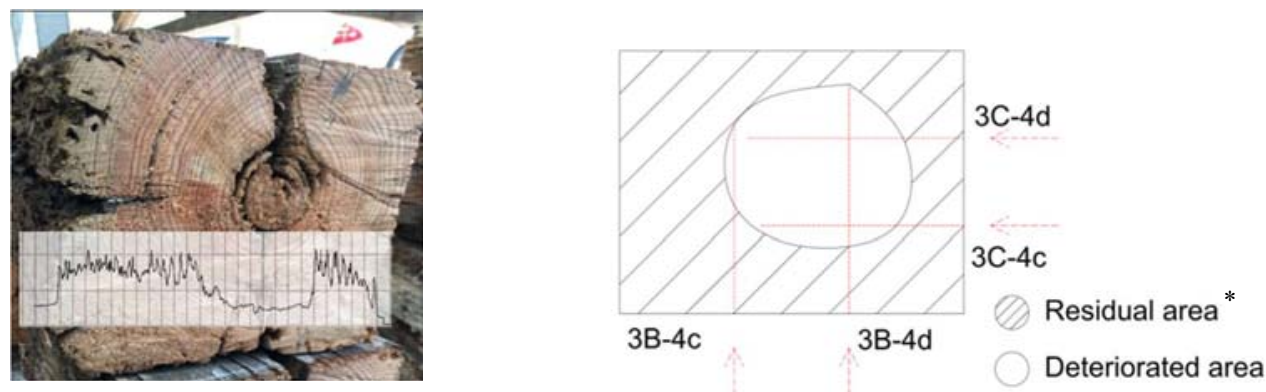

* The representation of the residual and deteriorated area corresponds to the results from the drilling resistance tests exclusively for the analysis of decay. However, it should be noted that for the calculation of the residual cross-section the existence of deep cracks was identified and their geometry measured.

Figure 4 - Example of the residual cross section map

3) Pin penetration test. Pin penetration test is a local semi-destructive test, that although having been originally designed to estimate wood surface density through the local hardness (on standing trees), is commonly used for assessing timber surface decay (Lourenço, et al. 2013) on-site. The hand-held device Pilodyn ${ }^{\circledR}$ 6J-2236 was adopted in this work. The same 85 segments considered in the drilling resistance tests were considered, each being tested on 24 different positions ( 6 for each face), as shown in Figure $3 \mathrm{~d})$. Penetration depth $(d)$ was measured as it is commonly used for indicating the deterioration and predicting timber properties. It is noted that the penetration depth considered in this work is the difference between the values obtained in each segment and the tests made to a reference position where the element was sound and presented no signs of decay. However, the main shortcoming of this test concern its localized and superficial measurement nature, as it only gives information of a point, with only few centimetres of penetration (Clarke and Squirrell, 1985). Hence, it has been used more frequently for qualitative assessment, or with the combination of other more global NDTs.

4) Ultrasound test. Ultrasound test is a global non-destructive test, basically measuring the travelling velocity of the ultrasound oscillatory waves it generates, which propagate through the analysed material. This method is widely used for structural assessment of masonry, concrete and also timber structures. In this work, a Pundit Lab (Proceq) device with $54 \mathrm{kHz}$ transducers was adopted, since the favourable frequency range for timber assessment lies between 20 to $500 \mathrm{kHz}$, due to the high signal attenuation from propagating in wood (Sousa, 2013). Direct and indirect test were carried out on the timber elements. The indirect measurements were performed on face A (the most decayed face) 
of each segment, and the direct measurements were performed from face A to face $\mathrm{C}$, as shown in Figure 3 b) and c). Moreover, another direct tests were done for Element 3 from face $B$ to face $D$, since the initial recorded velocities (from face A to face $C$ ) were abnormally low and with almost little variation. This phenomenon can be attributed to significant surface decay of Element 3, which resulted in the poor contact between the transducer and the timber element surface (Ross, 2015). A wax and oil based coupling agent was used to ensure a better contact between transducers and the decayed surfaces (Oliveira et al., 2015). Two parameters were considered in this work, the travelling velocity and dynamic modulus of elasticity, calculating according to equation 2 (Lear, 2005):

$$
E_{d y n}=v^{2} \rho
$$

where $E_{d y n}$ is the dynamic modulus of elasticity, $v$ is the velocity and $\rho$ is the density. Density was obtained based on the measurements of apparent volume and weight of each segment on a controlled environment leading to $12 \%$ moisture content of the specimen.

5) Acoustic Emission. Acoustic Emission (AE) detects the elastic waves which are generated by an energy release. Two main analysis methods for AE tests are the parameter analysis and the waveform analysis. AE has been applied in fracture study for steel and concrete, and recent researches have proved the efficiency of AE method in analysing timber structures (Kossakowski, 2009). In this work, apparatus consisting of four sensors (Vallen System), four preamplifiers (Vallen System), a data logger (NI-USB4431) for sound and vibration measurement, a multichannel chassis, and a PC for data management. The signal trigger, which has the energy release event, corresponded to the use of the pin penetration equipment, thus combining those two non-destructive tests. The arrangement is shown in Figure 3 e). Similar to the ultrasound tests, the tests between opposite sensors 0 and 3 are defined as direct tests, while those from parallel sensor 0 to 1 and 1 to 2 are indirect tests.

\subsubsection{Destructive tests}

1) Density measurement. After cutting the elements into $25 \mathrm{~cm}$ segments, density of measured on each segment, calculated according to EN 408+A1 (2010). 
2) Bending test in elastic range. The bending tests were carried out according to EN $408+$ A1 (2010). The global modulus of elasticity $\left(E_{\text {static }}\right)$ was calculated. Each element was subjected to three bending tests, with the tested length of $3450 \mathrm{~mm}$. As an example, Figure $3 \mathrm{f}$ ) shows the testing arrangement of Element 1 . In order to have a variation of stiffness along the length of the elements, middle parts of the elements were submitted to more than one test, and the stiffness was calculated as the average from those tests. It is important to note that a bending test is a destructive test when the member (test specimen) is taken to failure to obtain the bending strength. However, as the scope of this analysis was to obtain the bending $\mathrm{MoE}$, the test itself is not destructive. On the other hand, to perform this test it was needed to test the member removed from the structure thus its destructive nature.

\section{Results}

\subsection{Experimental results}

After the preliminary visual inspection, all the segments were first classified into four visual grade (I, II, III, and NC). Figure 5 a) shows the distribution of $E_{\text {static }}$ in terms of each visual grade. Figure 5 evidences that the mechanical performances of small, clear samples are influenced by density (Figure 5.b), whereas the presence of defects combined with the possible presence of decay, allows to infer on the mechanical properties of ondimension timber.

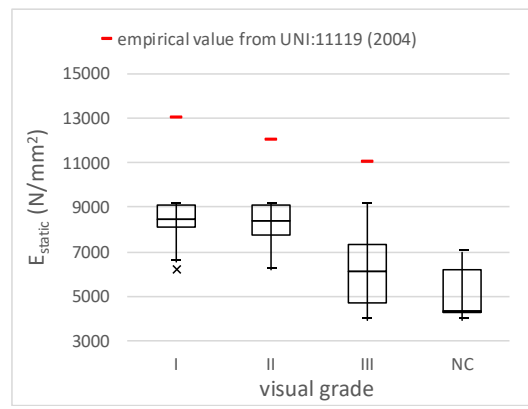

a)

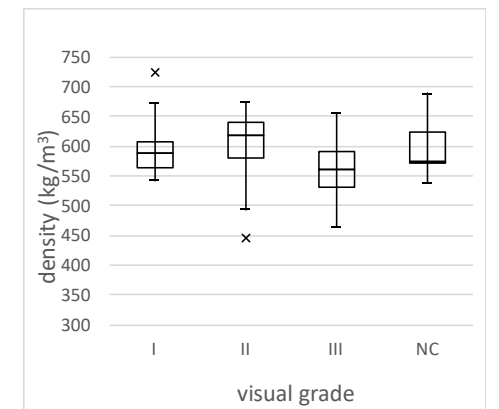

b)

Figure 5 - Results of tests to obtain reference properties of timber: a) static global modulus of elasticity; b) density

Although, in this case, the visual grading does not give conservative prediction of the $E_{\text {static }}$ it still provides a reference category in terms of the level of defects and decay. According to that premise, an outlier analysis was conducted for all the NDTs and DTs 
results based on each visual grade as shown in Figure 5 and 6. Mean values and coefficient of variation $(\mathrm{CoV})$ of each parameters were listed in Table 3.

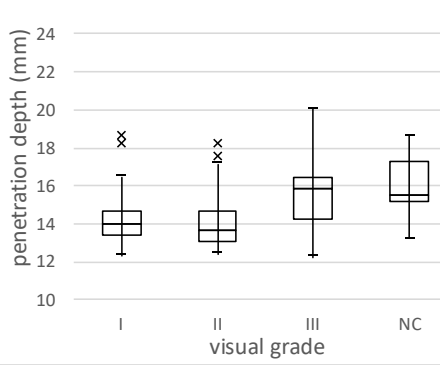

a)

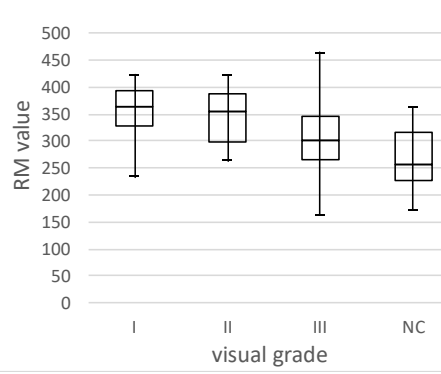

d)

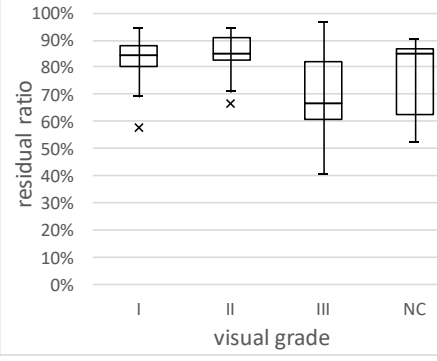

b)

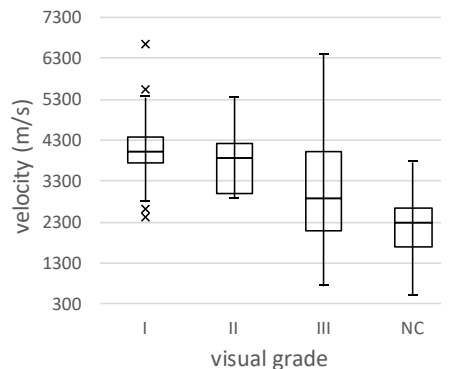

e)

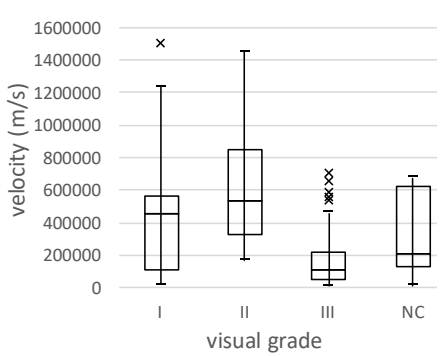

c)

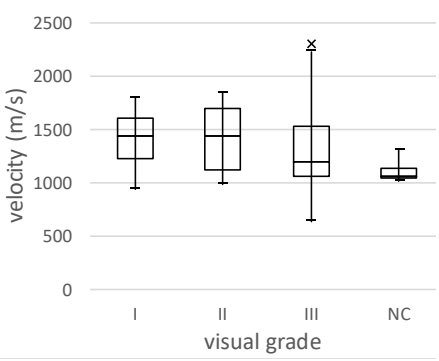

f)

Figure 6 - Results of NDTs: a) penetration depth; b) residual ratio; c) indirect AE velocity; d) RM value; e) direct ultrasound velocity; f) indirect ultrasound velocity.

Table 3 - Results of NDTs and DTs

\begin{tabular}{|c|c|c|c|c|c|c|c|c|c|}
\hline \multicolumn{2}{|c|}{ Parameter } & $\begin{array}{c}E_{\text {static }} \\
\left(\mathrm{N} / \mathrm{mm}^{2}\right)\end{array}$ & $\begin{array}{c}\rho \\
\left(\mathrm{kg} / \mathrm{m}^{3}\right)\end{array}$ & $\underset{(\mathrm{mm})}{\mathrm{d}}$ & $r$ & $\begin{array}{c}v \underset{A E-}{A \text { indirect }} \\
(\mathrm{m} / \mathrm{s})\end{array}$ & $\mathrm{R} M$ & $\begin{array}{l}v \text { vir- } \\
\text { direct } \\
(\mathrm{m} / \mathrm{s})\end{array}$ & 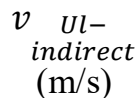 \\
\hline \multirow{2}{*}{ Overall } & Mean & 7515 & 581 & 15.0 & $77 \%$ & 366334 & 331 & 1367 & 3691 \\
\hline & $\mathrm{CoV}$ & 0.21 & 0.08 & 0.13 & 0.17 & 0.93 & 0.19 & 0.23 & 0.34 \\
\hline \multirow{2}{*}{$\begin{array}{l}\text { Visual } \\
\text { grade I }\end{array}$} & Mean & 8406 & 593 & 14.4 & $82 \%$ & 421369 & 354 & 1406 & 4055 \\
\hline & $\mathrm{CoV}$ & 0.09 & 0.06 & 0.10 & 0.11 & 0.84 & 0.14 & 0.17 & 0.23 \\
\hline \multirow{2}{*}{$\begin{array}{l}\text { Visual } \\
\text { grade } \\
\text { II }\end{array}$} & Mean & 8320 & 603 & 14.1 & $84 \%$ & 624462 & 349 & 1417 & 3788 \\
\hline & $\mathrm{CoV}$ & 0.11 & 0.09 & 0.12 & 0.10 & 0.59 & 0.15 & 0.21 & 0.22 \\
\hline \multirow{2}{*}{$\begin{array}{l}\text { Visual } \\
\text { grade } \\
\text { III }\end{array}$} & Mean & 6399 & 562 & 15.9 & $70 \%$ & 199969 & 304 & 1282 & 3248 \\
\hline & $\mathrm{CoV}$ & 0.26 & 0.07 & 0.13 & 0.21 & 1.06 & 0.22 & 0.31 & 0.49 \\
\hline
\end{tabular}

In terms of the distribution, resistance drilling and pin penetration tests are the ones with lower number of outliers, while the indirect acoustic and indirect ultrasound test exhibit a larger presence of outliers. Moreover, the results for both indirect and direct AE test are highly scattered. Around $25 \%$ of the tested points did not provide valid results in the direct $\mathrm{AE}$ test mainly due to the low surface contact due to decay. 
Furthermore, as shown in Table 4, two patterns of how the parameter values change with respect to the visual grade were observed: Pattern $I I>I>N C>I I I$ represented by density, and Pattern $I \approx I I>I I I>N C$ represented by $E_{\text {static. }}$. It must be noted that the tests not matching with the pattern obtained by $E_{\text {static }}$ may be either not sufficient to fully define (or be correlated) to the mechanical properties, may also be inversely correlated or simply being not suitable for application as a predictor of $E_{\text {static. }}$.

Table 4 - Typical change patterns in terms of visual grades

\begin{tabular}{|c|c|}
\hline Parameter & Pattern \\
\hline$E_{\text {static }}$ & $\mathrm{I} \approx I I>I I I>N C$ \\
\hline$R M$ & $\mathrm{I} \approx I I>I I I>N C$ \\
\hline$v_{U l-\text { direct }}$ & $\mathrm{I} \approx I I>I I I>N C$ \\
\hline$v_{U l-\text { indirect }} \approx I I>I I I>N C$ \\
\hline$\rho$ & $I I>I>N C>I I I$ \\
\hline $\mathrm{r}$ & $I I>I>N C>I I I$ \\
\hline$v_{A E-\text { indirect }}$ & $I I>I>N C>I I I$ \\
\hline$d$ & $I I<I<N C<I I I$ \\
\hline
\end{tabular}

\subsection{Linear regression correlation}

Linear correlations were built between the resultant parameters from NDTs and timber properties tested from DTs. The influence of the specimen size was taken into consideration by assuming the results obtained in a single or multiple segments. This means that since the elements were physically cut into $25 \mathrm{~cm}$ segment, the result values for larger segments as $50 \mathrm{~cm}, 75 \mathrm{~cm}$, and $100 \mathrm{~cm}$ were calculated by averaging the results of 2 or more continuous $25 \mathrm{~cm}$ segments. The coefficients of determination $\left(R^{2}\right)$ of each correlation are shown in Table 5. However, the analysis of the segment size effect was only conducted in terms of density, due to the insufficient database of $E_{\text {static, }}$ as only 9 bending tests were carried out, yielding 13 values in total. 
Table 5 - Summary of the linear correlations between non-destructive test parameters and mechanical properties of the timber elements

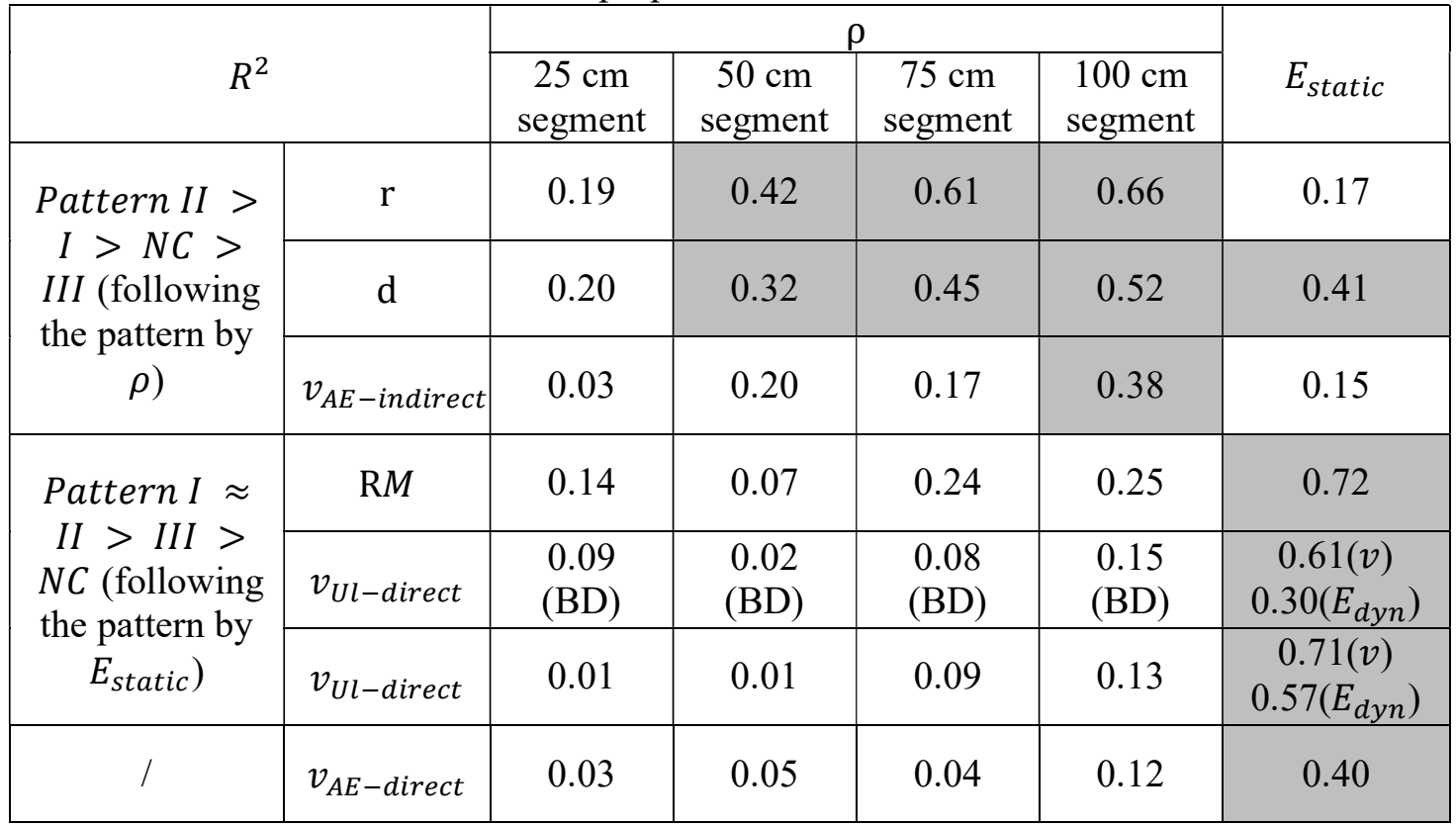

In the density analysis, the correlations for $25 \mathrm{~cm}$ segments were relatively poor, yet were significantly improved by enlarging the segment size, as the irregular values, either very low or very big, generated by local features can be minimized through averaging the test values along a longer segment. Moreover, the highest $R^{2}$ were given by residual ratio and penetration depth, and their change from $75 \mathrm{~cm}$ to $100 \mathrm{~cm}$ were not so significant. In that case, considering the accuracy and the number of analysis samples, $75 \mathrm{~cm}$ would be the most favourable choice.

In terms of the prediction ability, for density, moderate correlations $(75 \mathrm{~cm}$ segment) were provided by residual ratio $\left(R^{2}=0.61\right)$ and penetration depth $\left(R^{2}=0.45\right)$; and for $E_{\text {static }}$ reliable correlations were provided by the $R M\left(R^{2}=0.72\right)$ and indirect ultrasound velocity $\left(R^{2}=0.71\right)$. Moreover, as for the changing pattern of each tests in terms of the visual grade, it can be found that the NDTs which show the same change pattern as density or $E_{\text {static, }}$ are the ones that provide better correlations.

\subsection{Multiple regression correlation}

Multiple regression analysis was applied for different combination of tests. Adjusted coefficient of determination $\left(R_{a d j}^{2}\right)$, the modified version of $R^{2}$ adapted for the number of predictors, was adopt for comparison of prediction ability for the different test 
campaigns.

\subsubsection{Multiple regression analysis for density}

As concluded before, the $75 \mathrm{~cm}$ is the most favourable segment size, therefore the multiple regression for density was conducted with that value as presented in Table 6. Model 1 to 5 are the models that can be made when only one device is available onsite. In that case, the best predictor is given by the residual ratio $\left(R_{a d j}^{2}=0.72\right)$. Model $6,7,8$, 12 , and 13 reveal that no parameter could provide any significant contribution to the correlation between density and residual ratio. Through model 9, 10,11, 14 and 15, the best correlation when residual ratio is not available, would be given by the combination of penetration depth and $R M\left(R_{a d j}^{2}=0.72\right)$, slightly higher than penetration depth alone. Hence, in terms of prediction of density, as seen by the multiple regression analysis, the combination of tests did not produce any significant change.

Table 6 - Multiple regression values and parameters used for density prediction $(75 \mathrm{~cm}$ segments)

\begin{tabular}{|c|c|c|c|c|c|c|c|c|c|}
\hline & $\begin{array}{l}\overline{0} \\
\overline{0} \\
\Sigma\end{array}$ & $\nabla$ & $\Sigma$ & $=$ & 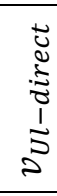 & 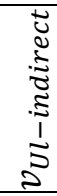 & 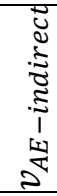 & 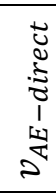 & $R_{a d j}^{2}$ \\
\hline \multirow{5}{*}{ 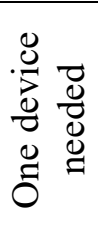 } & 1 & $\checkmark$ & & & & & & & 0.42 \\
\hline & 2 & & & $\checkmark$ & & & & & 0.72 \\
\hline & 3 & & $\checkmark$ & $\checkmark$ & & & & & 0.72 \\
\hline & 4 & & & & $\checkmark$ & $\checkmark$ & & & 0.13 \\
\hline & 5 & & & & & & $\checkmark$ & $\checkmark$ & 0.12 \\
\hline \multirow{10}{*}{$\begin{array}{l}\overrightarrow{0} \\
\mathbb{8} \\
0 \\
0 \\
0 \\
0 \\
0 \\
0 \\
0 \\
0 \\
0 \\
0 \\
0\end{array}$} & 6 & $\checkmark$ & & $\checkmark$ & & & & & 0.70 \\
\hline & 7 & & & $\checkmark$ & $\checkmark$ & & & & 0.71 \\
\hline & 8 & & & $\checkmark$ & & & $\checkmark$ & & 0.71 \\
\hline & 9 & $\checkmark$ & $\checkmark$ & & & & & & 0.45 \\
\hline & 10 & $\checkmark$ & & & $\checkmark$ & & & & 0.38 \\
\hline & 11 & $\checkmark$ & & & & & $\checkmark$ & & 0.42 \\
\hline & 12 & & & $\checkmark$ & $\checkmark$ & $\checkmark$ & & & 0.40 \\
\hline & 13 & & & $\checkmark$ & & & $\checkmark$ & $\checkmark$ & 0.70 \\
\hline & 14 & $\checkmark$ & & & $\checkmark$ & $\checkmark$ & & & 0.41 \\
\hline & 15 & $\checkmark$ & & & & & $\checkmark$ & $\checkmark$ & 0.40 \\
\hline
\end{tabular}

\subsubsection{Multiple regression analysis for $E_{\text {static }}$}

The results of multiple regression analysis for $E_{\text {static }}$ are shown in Table 7. As concluded 
from the linear correlation, the residual ratio and indirect $\mathrm{AE}$ velocity have little correlation with bending stiffness, hence they were not considered in most of the test combinations.

Table 7 - Multiple regression values and parameters used for $E_{\text {static }}$ prediction

\begin{tabular}{|c|c|c|c|c|c|c|c|c|c|}
\hline & $\begin{array}{l}\overline{0} \\
\bar{\delta} \\
\Sigma\end{array}$ & $\sigma$ & $\underset{\Omega}{\Sigma}$ & $=$ & 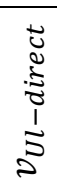 & 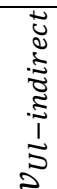 & 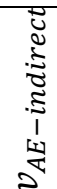 & 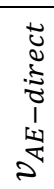 & $R_{a d j}^{2}$ \\
\hline \multirow{6}{*}{ 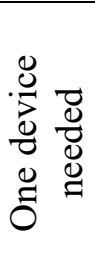 } & 1 & $\checkmark$ & & & & & & & 0.35 \\
\hline & 2 & & & & & $\checkmark$ & & & 0.68 \\
\hline & 3 & & $\checkmark$ & & & & & & 0.69 \\
\hline & 4 & & $\checkmark$ & $\checkmark$ & & & & & 0.66 \\
\hline & 5 & & & & $\checkmark$ & $\checkmark$ & & & 0.72 \\
\hline & 6 & & & & & & $\checkmark$ & $\checkmark$ & 0.30 \\
\hline \multirow{8}{*}{ 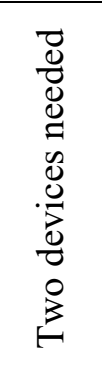 } & 7 & $\checkmark$ & $\checkmark$ & & & & & & 0.67 \\
\hline & 8 & & $\checkmark$ & & $\checkmark$ & & & & 0.77 \\
\hline & 9 & & $\checkmark$ & & & $\checkmark$ & & & 0.77 \\
\hline & 10 & & $\checkmark$ & & & & & $\checkmark$ & 0.82 \\
\hline & 11 & $\checkmark$ & & & & $\checkmark$ & & & 0.71 \\
\hline & 12 & & & & & $\checkmark$ & & $\checkmark$ & 0.76 \\
\hline & 13 & & $\checkmark$ & & $\checkmark$ & $\checkmark$ & & & 0.79 \\
\hline & 14 & $\checkmark$ & & & $\checkmark$ & $\checkmark$ & & & 0.69 \\
\hline
\end{tabular}

From model 1 to 3, when only one device is available, the $R M$ or ultrasound direct velocity can already provide moderate correlation. Moreover, for ultrasound test, if combining the indirect and direct ultrasonic velocity, the correlation can be slightly improved, yet for the resistance drilling test, combining two parameters gives no improvement.

Comparing model 7 to 10 with model 3 , the correlation involving $R M$ would be much improved if supplied with another parameter (except for pin penetration). The highest $R_{a d j}^{2}$ was obtained by $R M$ and direct $\mathrm{AE}$ velocity, equalling to 0.82 . As for pin penetration test, as shown in model 7, 11 and 14, it hardly provides improvement to the correlation as a supplement for other tests.

Since reliable correlation could already be obtained from the combinations of two devices, the models which would require three or more devices were not considered. 


\subsection{Decay assessment}

\subsubsection{Decay and defect interpretation}

According to the visual inspection, decay and defects were classified into three levels of presence: low, medium and high. For decay by insects and fungi and defects as ringshake, as shown in Table 8, low presence stands for where only local small holes superficial fissures are exhibited, medium is when the decay is visible but the defect/decayed area is less than half of the whole section, and high presence is where the defect/decayed area is more than half of the whole section. For defects as knots, the severity level is determined corresponding to the visual grade criterial in UNI:11119 low presence corresponds to visual grade I, medium presence corresponds to II, and high presence corresponds to III and NC.

Table 8 - Different levels of defect and decay

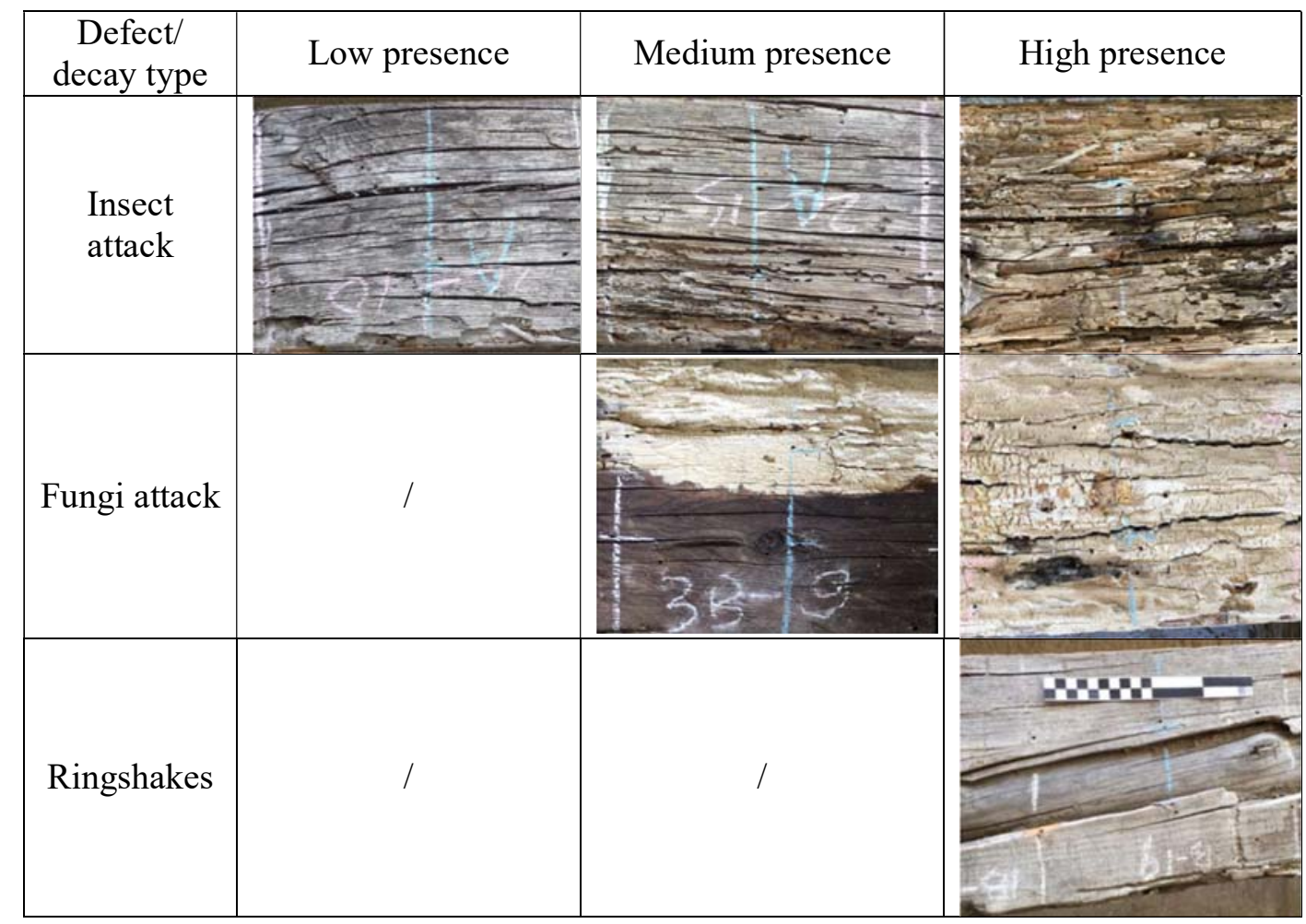

In general, insect attack is prevailing along all three elements with various level of presence. Ringshake is also present in all three elements, yet most of them are combined with medium to high level of fungi or insect attack, making it difficult to isolate its influence along the element. 
Fungi attack, however, was only found in Element 3. Moreover, from the residual cross section map made from resistance drilling tests, all segments with superficial fungi also presented severe inner rot, as shown in Figure 7. Hence, in this work, the mentioned fungi attack is specifically referring to the combination of surface and indepth attack.

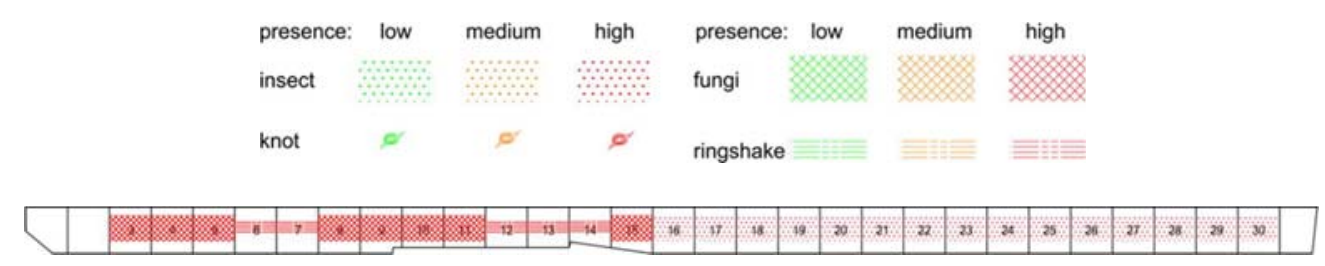

a)

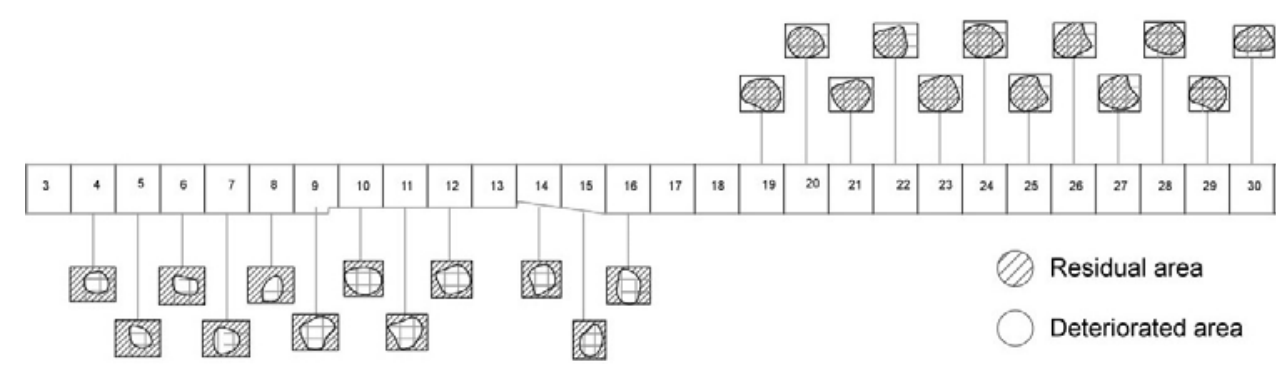

b)

Figure 7 - Decay interpretation of Element 3: a) defect map; b) residual cross section map

\subsubsection{Influence of decay and defects to NDT and DT results}

By classifying all the segments into different groups according to the defect and decay presence and comparing the resultant parameters, the influence of defect and decay to NDT results and timber properties are summarized in Table 9.

The presence of fungi or insects was found to lower all the test results. The influence of ringshake, as it always presents along with other defects, only influenced the results of the local tests, namely drilling resistance and pin penetration tests. Knots, which are commonly the main parameter considered to influence timber properties, tend to decrease most of the NDT results, yet a large concentration is actually also increasing the density.

More importantly, Table 9 shows a rough estimation of how strong the influences from different defects and decays are. As the change of wood properties ( $\rho$ and $E_{\text {static }}$ ) are the combination of all these influences with different contribution levels, this table 
explains why it is hard for NDT to achieve reliable correlation to timber properties, especially when only a single parameter is used.

Table 9 - Influence of defect and decay to NDTs and timber properties

\begin{tabular}{|c|c|c|c|c|}
\hline & Knot & Fungi & Insect & Ringshakes \\
\hline$\rho$ & Increase & $\begin{array}{c}\text { Decrease } \\
\text { (strongly) }\end{array}$ & Decrease & $/$ \\
\hline$E_{\text {static }}$ & $\begin{array}{c}\text { Decrease } \\
\text { (slightly) }\end{array}$ & $\begin{array}{c}\text { Decrease } \\
\text { (strongly) }\end{array}$ & Decrease & Decrease \\
\hline$R M$ & Decrease & $\begin{array}{c}\text { Decrease } \\
\text { (strongly) }\end{array}$ & Decrease & Decrease \\
\hline$d$ & Not significant & $\begin{array}{c}\text { Increase } \\
\text { (strongly) }\end{array}$ & $\begin{array}{c}\text { Increase } \\
\text { (strongly) }\end{array}$ & Not significant \\
\hline$v_{U l-\text {-indirect }}$ & Decrease & $\begin{array}{c}\text { Decrease } \\
\text { (strongly) }\end{array}$ & $\begin{array}{c}\text { Decrease } \\
\text { (strongly) }\end{array}$ & $/$ \\
\hline$v_{U l-\text { direct }}$ & $\begin{array}{c}\text { Decrease } \\
\text { (slightly) }\end{array}$ & $\begin{array}{c}\text { Abnormally } \\
\text { low value }\end{array}$ & $\begin{array}{c}\text { Decrease } \\
\text { (slightly) }\end{array}$ & $/$ \\
\hline$v_{A E-\text { indirect }}$ & Increase & $\begin{array}{c}\text { Decrease } \\
\text { (slightly) }\end{array}$ & $/$ \\
\hline$v_{A E-\text { direct }}$ & Decrease & $\begin{array}{c}\text { Decrease } \\
\text { (strongly) }\end{array}$ & $/$ & $/$ \\
\hline
\end{tabular}

\subsubsection{Correlations with presence of fungi}

According to the decay interpretation, only 14 segments $(25 \mathrm{~cm})$ were presented with fungi attack, yet the number was not sufficient to build correlations for a group only with fungi attack. In that case, to analyse its influence, the correlations were built for two groups, the overall group and the group excluding the fungi attacked ones. Results are shown in Table 10. Direct ultrasound test was not considered in this analysis as no valid signal was detected in the fungi attacked segments.

Table 10 - Summary of $R^{2}$ with density in comparison with fungi attack

\begin{tabular}{|c|c|c|c|c|}
\hline \multirow{2}{*}{$R^{2}$} & \multicolumn{2}{|c|}{$50 \mathrm{~cm}$ segments } & \multicolumn{2}{c|}{$75 \mathrm{~cm}$ segments } \\
\cline { 2 - 5 } & Overall & Free of fungi attack & Overall & Free of fungi attack \\
\hline$r$ & 0.42 & 0.67 & 0.61 & 0.76 \\
\hline$d$ & 0.32 & 0.39 & 0.45 & 0.46 \\
\hline$v_{A E-\text { indirect }}$ & 0.20 & 0.20 & 0.17 & 0.19 \\
\hline$R M$ & 0.07 & 0.08 & 0.24 & 0.23 \\
\hline$v_{U l-\text { indirect }}$ & 0.01 & 0.05 & 0.09 & 0.17 \\
\hline$v_{A E-\text { direct }}$ & 0.05 & 0.03 & 0.04 & 0.02 \\
\hline
\end{tabular}


For the two best predictors for density, residual ratio and penetration depth, excluding the fungi attack segments generally improve the correlation. Moreover, the improvement was more significant for the residual ratio.

Although correlations within the segments exhibited fungi still need further research with a larger database to determine, from the conclusion above, a preliminary fungi inspection is highly recommended for in-situ NDT assessment of timber property, in order to achieve a more reliable prediction.

\subsubsection{Correlations with presence of insect attack}

To analyse the influence of insect attack, three groups were considered, specified as the Overall, the Free of insect which is consisted of the segments with non or low level presence of insect attack, the Insect attacked which are the segments with medium or high level presence.

Table 11 shows the summary of linear correlations. As a conclusion, three types of influence of insect attack on predictability can be observed. The first one, including residual ratio, penetration depth and indirect $\mathrm{AE}$ velocity, showed significant improvement in Insect attacked. For poor predictors as direct and indirect ultrasound velocity, no significant change can be observed between groups. Lastly, for $R M$, moderate correlation was found in Free of insect, yet almost no correlation was found in Insect attacked. In that case, $R M$ could be more useful for interpreting new sawn timber.

Table 11 - Summary of $R^{2}$ with density in comparison with insect attack

\begin{tabular}{|c|c|c|c|c|c|c|}
\hline \multirow{2}{*}{$R^{2}$} & \multicolumn{3}{|c|}{50 cm segments } & \multicolumn{3}{c|}{$75 \mathrm{~cm}$ segments } \\
\cline { 2 - 7 } & $\begin{array}{c}\text { Free of } \\
\text { insect }\end{array}$ & $\begin{array}{c}\text { Insect } \\
\text { attacked }\end{array}$ & Overall & $\begin{array}{c}\text { Free of } \\
\text { insect }\end{array}$ & $\begin{array}{c}\text { Insect } \\
\text { attacked }\end{array}$ & Overall \\
\hline$r$ & 0.50 & 0.49 & 0.51 & 0.59 & 0.87 & 0.74 \\
\hline$d$ & 0.24 & 0.26 & 0.31 & 0.03 & 0.68 & 0.54 \\
\hline$v_{A E-\text { indirect }}$ & 0.04 & 0.35 & 0.14 & 0.00 & 0.51 & 0.17 \\
\hline$v_{U l-\text { indirect }}$ & 0.04 & 0.10 & 0.03 & 0.00 & 0.01 & 0.02 \\
\hline$v_{U l-\text { direct }}$ & 0.00 & 0.22 & 0.14 & 0.00 & 0.09 & 0.08 \\
\hline$R M$ & 0.32 & 0.00 & 0.11 & 0.35 & 0.02 & 0.17 \\
\hline
\end{tabular}

\section{Conclusions}

In this work, three timber elements from two historic timber trusses, with presence of different types of decay were extensively tested by using different NDTs and DTs. Correlations analysis were built between the resultant parameters and the timber 
properties. Although the small sample size in terms of elements, the analysis was made accounting several segments of each element, thus increasing the overall sample size. Nevertheless, the results must be taken with caution as they are representative of this sample, but the framework here presented can be applied to different situations.

Generally, as for the best predictors, resistance drilling and pin penetration tests perform as the best for density indication, while ultrasound and resistance drilling tests give rather reliable prediction for modulus of elasticity. However, AE tests show very scattered results which is due to their high sensitivity, were not suitable to assess the level of decay in this study.

To further refine the model, the size of the specimen, the contribution of multiple parameters, and the presence of decay were analysed.

Firstly, larger segment size is preferred as it reduce the abnormal values from very local effects through averaging the result values. However, in practice, $75 \mathrm{~cm}$ would be favourable in order to retain sufficient number of samples.

In terms of the multiple regression analysis, using more than one parameter do not necessary give higher coefficients of determination, thus concluding that the option to combine results of non-destructive tests must be made with caution. Even if all tests provide different type of information, the aim of the analysis must be first defined in order to understand what are the most suitable tests. For density assessment, residual ratio along yield highest $R_{a d j}^{2}$, yet for $E_{\text {static }}$, although reliable correlation can already be achieved by single parameter, some combinations can still improve the model.

The decay assessment was only made for the fungi and insect attack as limited by the database. The presence of fungi decreases the predictability of residual ratio and penetration depth, while the presence of insect attack exhibits three types of the influences on different NDTs parameters. In that case, the preliminary visual inspection for identifying the timber decay is highly recommended for on-site timber assessment, since by classifying timber elements according to the level of decay, higher coefficients of determination can be obtained.

\section{Acknowledgments}

This work was partly financed by FEDER funds through the Competitivity Factors Operational Programme - COMPETE and by national funds through FCT (Foundation for Science and Technology) within the scope of the project POCI-01-0145- 
FEDER-007633. The financial support of FCT, through national funds, within the scope of the project Protimber, PTDC/ECM-EST/1072/2014, is acknowledged.

\section{References}

Branco JM, Piazza M, and Cruz PJS. Structural analysis of two King-post timber trusses: Non-destructive evaluation and load-carrying tests. Construction and Building Materials. 2010; 24: 371-383.

Branco JM, Sousa HS, Tsakanika E. Non-destructive assessment, full-scale load-carrying tests and local interventions on two historic timber collar roof trusses. Engineering Structures. 2017 Jun 1; 140: 209-24.

Cavalli A, Bevilacqua L, Capecchi G, Cibecchini D, Fioravanti M, Goli G, Togni M, Uzielli L. MOE and MOR assessment of in service and dismantled old structural timber. Engineering Structures. 2016 Oct 15; 125: 294-9.

Cavalli A, Togni M. How to improve the on-site MOE assessment of old timber beams combining NDT and visual strength grading. Nondestructive testing and evaluation. 2013 Sep 1; 28(3): 252-62.

CEN. EN 408+A1: Timber Structures - Structural Timber and Glued Laminated Timber - Determination of Some Physical and Mechanical Properties. 2010.

Clarke RW, Squirrell JP. The Pilodyn: An Instrument for Assessing the Condition of Waterlogged Wooden Objects. Studies in Conservation. 1985; 30(4): 177-183.

Cruz H, Yeomans D, Tsakanika E, Macchioni N, Jorissen A, Touza M, Mannucci M, Lourenço PB. Guidelines for on-site assessment of historic timber structures. International Journal of Architectural Heritage. 2015; 9(3): 277-89.

García-Iruela A, Fernández FG, Esteban LG, de Palacios P, Simón C, Arriaga F. Comparison of modelling using regression techniques and an artificial neural network for obtaining the static modulus of elasticity of Pinus radiata D. Don. timber by ultrasound. Composites Part B: Engineering. 2016 Jul 1; 96:112-8.

Gomes ID, Kondis F, Sousa HS, Branco JM, Lourenço PB. Assessment and diagnosis of two collar timber trusses by means of visual grading and non-destructive tests. InHistorical Earthquake-Resistant Timber Framing in the Mediterranean Area 2016 (pp. 311-320). Springer, Cham.

JCSS Probabilistic Model Code, Part 3: Resistance Models - 3.5 Properties of Timber. Probabilistic Model Code, Joint Committee on Structural Safety. 2006. 
Kasal B, Tannert T. In situ assessment of structural timber. Springer Dordrecht Heidelberg London New York. 2010

Kawamoto S, Williams RS. Acoustic emission and acousto-ultrasonic techniques for wood and wood-based composites: a review. Gen. Tech. Rep. FPL-GTR-134. Madison, WI: US Department of Agriculture, Forest Service, Forest Products Laboratory. 16 p.. 2002; 134.

Kloiber M, Drdácký M, Tippner J, Hrivnák J. Conventional compressive strength parallel to the grain and mechanical resistance of wood against pin penetration and microdrilling established by in-situ semidestructive devices. Materials and Structures. 2015; 48(10), 3217-3229.

Kossakowski P. Application of the acoustic emission method in order to determine the crack initiation moment in timber. Structure and Environment. 2009; 1(1): 11-16.

Lamy F, Takarli M, Angellier N, Dubois F, Pop O. Acoustic emission technique for fracture analysis in wood materials. International Journal of Fracture. 2015 Mar 1;192(1):57-70.

Lear GC. Improving the assessment of in situ timber members with the use of nondestructive and semi-destructive testing techniques [master's thesis]. Raleigh: North Carolina State University; 2005.

Lourenço PB, Sousa HS, Brites RD, Neves LC. In situ measured cross section geometry of old timber structures and its influence on structural safety. Materials and structures (Springer Netherlands). 2013; 46 (7): 1193-1208.

Miguel EP, de Melo RR, Junior LS, Del Menezzi CH. Using artificial neural networks in estimating wood resistance. Maderas. Ciencia y Tecnología. 2018 Mar 3; 20(4).

Morales-Conde MJ, Machado JS. Evaluation of cross-sectional variation of timber bending modulus of elasticity by stress waves. Construction and Building Materials. 2017 Mar 1; 134: 617-25.

Nowak TP, Jasieńko J, Hamrol-Bielecka K. In situ assessment of structural timber using the resistance drilling method-evaluation of usefulness. Construction and Building Materials. 2016; 102: 403-415.

Oliveira M, Sousa HS, Branco JM, Lourenço PB. Comparative ultrasound performance in the non-destructive evaluation of Chestnut timber. RPEE Revista Portuguesa de Engenharia de Estruturas. 2015; series II(14): 31-44 (in Portuguese).

Riggio M, D'Ayala D, Parisi MA, Tardini C. Assessment of heritage timber structures: Review of standards, guidelines and procedures. Journal of Cultural Heritage. 2018; 31: 220-235. 
Ross RJ, editor. Nondestructive evaluation of wood. Government Printing Office; 2015.

Ruy M, Gonçalves R, Pereira DM, Lorensani RG, Bertoldo C. Ultrasound grading of round Eucalyptus timber using the Brazilian standard. European Journal of Wood and Wood Products. 2018 May 1;76(3):889-98.

Salmi A, Karppinen T, Montonen R, Saranpää P, Hæggström E. Ultrasonic estimate of the modulus of rupture and quantification of the frequency dependent dynamic modulus in Norway Spruce. Journal of Applied Physics. 2013 Jan 14;113(2): 024904.

Sousa HS, Branco JM, Lourenço PB. A holistic methodology for probabilistic safety assessment of timber elements combining onsite and laboratory data. International Journal of Architectural Heritage. 2016, Jul 3;10(5):526-38.

Sousa HS, Branco JM, Silva CV. Visual assessment and diagnosis of a timber railway station warehouse in Foz do Tua. International Wood Products Journal. 2017 Aug 21; 8(sup1): 29-33.

Sousa HS, Machado JS, Branco JM, Lourenço PB. Onsite assessment of structural timber members by means of hierarchical models and probabilistic methods. Construction and Materials. 2015; 101: 1188-1196.

Sousa HS, Prieto-Castrillo F, Matos JC, Branco JM, Lourenço PB. Combination of expert decision and learned based Bayesian Networks for multi-scale mechanical analysis of timber elements. Expert Systems with Applications. 2018 Mar 1; 93: 156-68.

Sousa HS. Methodology for safety evaluation of existing timber elements. University of Minho [dissertation]. Guimarães: University of Minho; 2013.

UNI. UNI 11119. Cultural Heritage - Wooden Artifacts - Load-Bearing Structures - On Site Inspections for the Diagnosis of Timber Members. Milano: Ente Nazionale Italiano di Unificazione. 2004.

Vega A, Dieste A, Guaita M, Majada J, Baño V. Modelling of the mechanical properties of Castanea sativa Mill. structural timber by a combination of non-destructive variables and visual grading parameters. European Journal of Wood and Wood Products. 2012 Nov 1;70(6):839-44.

Zhang J, Xu QF, Xu YX, Zhang M. Research on residual bending capacities of used wood members based on the correlation between non-destructive testing results and the mechanical properties of wood. Journal of Zhejiang University-SCIENCE A. 2015 Jul 1; 16(7): 541-50. 